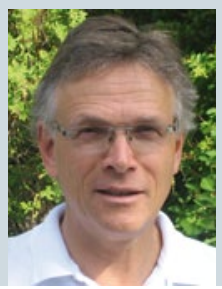

Dr. med.

Ulrich

Mutschler,

Hildesheim

\title{
Welche Injektionsstelle ist besser: Arm oder Bein?
}

\section{Um herauszufinden, welche Injektionsstelle für Routineimpfungen in der Altersgruppe von eins bis sechs Jahren zu bevorzugen ist, hat eine Arbeits- gruppe von 13 Autoren aus verschiedenen Großstädten der amerikanischen Westküste eine große Datenbank ausgewertet.}

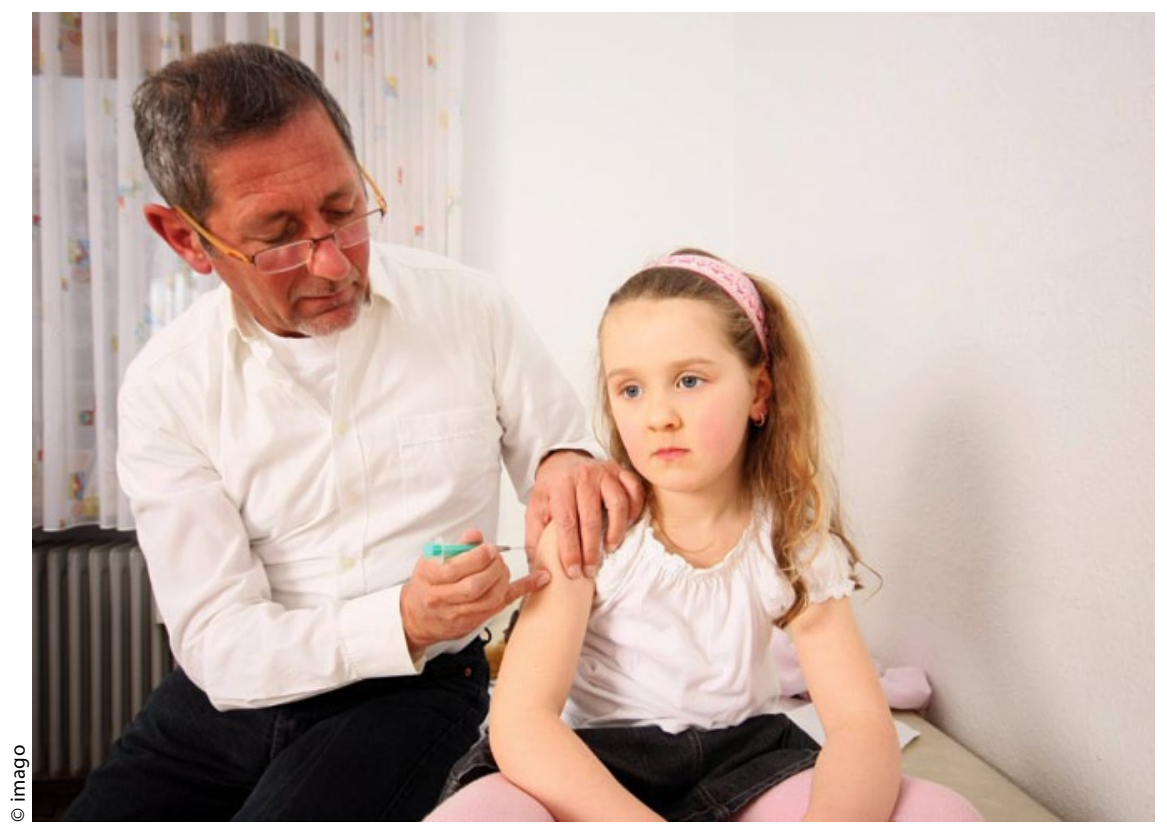

Gerade bei älteren Kindern kommt die Spritze gerne in den M. deltoideus.

im Alter von zwölf Monaten bis zwei Jahren Impfungen in den M. vastus lateralis zu verabreichen. Bei älteren Kindern kann der M. deltoideus gewählt werden, wenn die Muskelmasse angemessen ist. Jedoch gab es schon früher Hinweise, dass es nach Impfungen am Arm in der Altersgruppe von vier bis sechs Jahren häufiger zu lokalen Reaktionen kommt verglichen mit Injektionen am Bein.
US-amerkanische Wissenschaftler untersuchten nun, welche Stelle zu bevorzugen ist: Arm oder Bein. Die Kohortenstudie umfasste 1,4 Millionen Kinder und 9,3 Millionen (!) Impfungen. Von diesen Impfungen wurden 6 Mio. intramuskulär verabfolgt. Bei 5,6 Mio. Injektionen war die Injektionsstelle dokumentiert. Es handelt sich um folgende Impfungen: DTaP, Hepatitis A und Influenza. Die Studie war retrospektiv angelegt. Es wurden nur Lokalreaktionen erfasst, die zu einer Vorstellung des Kindes beim Arzt geführt haben.

Es wurden dann die Fälle evaluiert, bei denen nur ein Impfstoff allein ohne begleitende andere Impfungen verabreicht worden waren. Mit steigendem Alter wurden zunehmend mehr Injektionen in den Arm gegeben. Die Identifizierung der Lokalreaktion erfolgte nach einem dokumentierten ICD-Code (unter anderem für Gliedmaßenschwellung, Schmerzen in einer Gliedmaße, Cellulitis und Lymphadenitis).

Die Autoren der Studie stellten fest, dass in der Altersgruppe der Ein- bis Dreijährigen Lokalreaktionen bei Injektion im Arm um 88 \% häufiger waren als im Bein. Dies bezieht sich ausschließlich auf die Impfung mit DTaP-Impfstoff. Für Influenza- und Hepatitis-A-Impfstoff sind keine Unterschiede nachweisbar. In der Altersgruppe der Drei- bis Sechsjährigen ist die Häufigkeiten von Lokalreaktionen nach Impfung am Arm ebenfalls höher. Der Unterschied ist jedoch nicht statistisch signifikant.

Jackson LA et al. Vaccination site and risk of local reactions in children 1 through 6 years of age. Pediatrics 2013; 131: 283-9

Kommentar: Die Schlussfolgerung aus der Studie, die mit außerordentlich hohen Fallzahlen aufwartet, ist eindeutig: In der Altersgruppe von ein bis drei Jahren sollte Impfstoff, der die Komponenten DTaP enthält, in das Bein gespritzt werden. Für diese Aussage dürfte keine Rolle spielen, dass in den USA der in Deutschland übliche Sechsfachimpfstoff nicht zur Verfügung steht. Die Influenzaimpfung kann auch bei jungen Kleinkindern in den Arm erfolgen.

Dr. Hartmut Koch 